\title{
Inverted reamer technique for bone grafting of the acetabulum: technical note
}

\author{
Yuki Okutani ${ }^{1}$, Hiroshi Fujita ${ }^{2}$, Hideto Harada ${ }^{1}$, Masanao Kataoka ${ }^{1}$, Yu Shimizu ${ }^{3}$ and Yoshiki Murotani ${ }^{4}$
}

\begin{abstract}
Background: Socket fixation with bone grafting for dysplastic hips is technically demanding, and inadequate coverage of the socket may cause poor results in patients with severely dysplastic hips. An accurate technique to form a bone graft to fit into the defect is necessary. We aim to introduce the simple method of bone grafting,"inverted reamer technique" in cemented total hip arthroplasty (CTHA).

Methods: After acetabular preparation with a normal acetabular reamer, the bone graft was prepared from the resected femoral head with the inverted reamer. The graft can be press-fit into the defect of the acetabulum with good compatibility through this method. Then, the bone graft was fixed with 1-3 screws and the socket was implanted with bone cement.
\end{abstract}

Results: The "inverted reamer technique" can easily and automatically create a well-fit graft. This method is simple and technically less demanding; it can be performed by every surgeon, including trainee and inexperienced surgeons.

Conclusion: This method can improve the outcome of cTHA for dysplastic hips by preserving bone stock and increasing bone coverage of the socket implanted in the anatomic position.

Keywords: Total hip arthroplasty, Cement, Bone graft, Inverted reamer, Dysplasia

\section{Introduction}

Total hip arthroplasty (THA) is one of the most successful treatments for hip dysfunction, and many excellent outcomes have been previously reported with this technique [1-5]. THA is divided into three types according to the fixation method: cemented, hybrid, or cementless. For cemented THA (cTHA), some studies have shown in comparison with problems of the femoral stem, socket problems more frequently require revision procedures [5-8]. This outcome might be improved by the development of highly crosslinked polyethylene (HXLPE), which reduces polyethylene wear $[9,10]$. Moreover, robust socket fixation is sometimes difficult, especially

\footnotetext{
*Correspondence: hfshoot@gmail.com

${ }^{2}$ Center for Hip and Knee Arthroplasty, Department of Orthopaedic

Surgery, Kyoto Rakuyo Hospital, Iwakura-Agura-cho 143, Sakyo-ku, Kyoto 606-0017, Japan

Full list of author information is available at the end of the article
}

in dysplastic hips, because of the massive bony defect of the acetabulum. Thus, successful cTHA requires an improved socket-fixation technique. Socket fixation with bone grafting for dysplastic hips is technically demanding, and inadequate coverage of the socket may cause poor results in patients with severely dysplastic hips [11]. Bone grafting can increase bone stock, improving the bone coverage of the socket and facilitating cement pressurization. However, a previous report showed that the 11.8-year incidence of loosening of the acetabular socket with bone grafting was high for dysplastic hips, and bone grafting for dysplastic hips is only recommended in cases with a massive bone defect [12]. In contrast, some other reports have shown good outcomes with bone grafting [13-15]. To ensure successful bone grafting, an accurate technique to form a bone graft to fit into the defect is necessary: however, this step is extremely technically demanding. Thus, we developed a new simpler method, in which the curvature of the bone graft is matched to original author(s) and the source, provide a link to the Creative Commons licence, and indicate if changes were made. The images or other third party material in this article are included in the article's Creative Commons licence, unless indicated otherwise in a credit line to the material. If material is not included in the article's Creative Commons licence and your intended use is not permitted by statutory regulation or exceeds the permitted use, you will need to obtain permission directly from the copyright holder. To view a copy of this licence, visit http://creativecommons.org/licenses/by/4.0/. The Creative Commons Public Domain Dedication waiver (http://creativeco mmons.org/publicdomain/zero/1.0/) applies to the data made available in this article, unless otherwise stated in a credit line to the data. 
that of the bone defect on the roof of the acetabulum using inverted reamers, which were introduced for cartilage removal of a femoral head [16, 17], such that the bone graft is well-fitted to the roof of the acetabulum. As a result, bone grafting is achieved mechanically, easily, and quickly. In this note, we will introduce this simple method of bone grafting.

\section{Method}

Bone defects are usually recognized on the roof of the acetabulum. These defects necessitate the creation of a bone graft to fit into the defect by trimming with instruments, including a bar or bone luer. However, a tight, stable fit of the graft with may be difficult to achieve with this conventional method. As an alternative, our method allows easy creation of a bone graft that is a good fit for the defect. The "inverted reamer technique" is described in more detail below:

\section{Indications for bone grafting for the acetabulum}

The need for bone grafting is determined during the operation. At our institute, bone grafting of the acetabulum is performed when the height between the lateral-cranial edge of the acetabulum and the lateral edge of the socket is more than $10 \mathrm{~mm}$ after reaming the acetabulum until the socket with the preoperatively planned size is set just on the transverse ligament (this procedure is called "anatomical placement").

2. Surgical approach to the acetabulum

At our institute, cTHA is performed with a modified Dall's approach in the lateral decubitus position [18, 19]. The cTHA procedure has been described briefly in a previous report [20]. The entire acetabulum is visualized with a pin-retractor placed in the ilium and a horizontal retractor.

3. Acetabulum preparation

The acetabulum is reamed until the sclerotic bone plate is removed and trabecular bone with fresh bleeding is recognized (Fig. 1a, 2a). Osteophytes and capsules around the acetabulum are removed completely in order to observe the true acetabulum and determine the graft size. The roof of the acetabulum, where the bone graft is eventually transplanted, is reamed by a normal acetabular reamer. Consequently, the sclerotic bone is removed, and the cancellous bone, which is active and vascular, is exposed. At this point, the reamer should be stabilized to obtain a complete spherical shape on the roof consid-

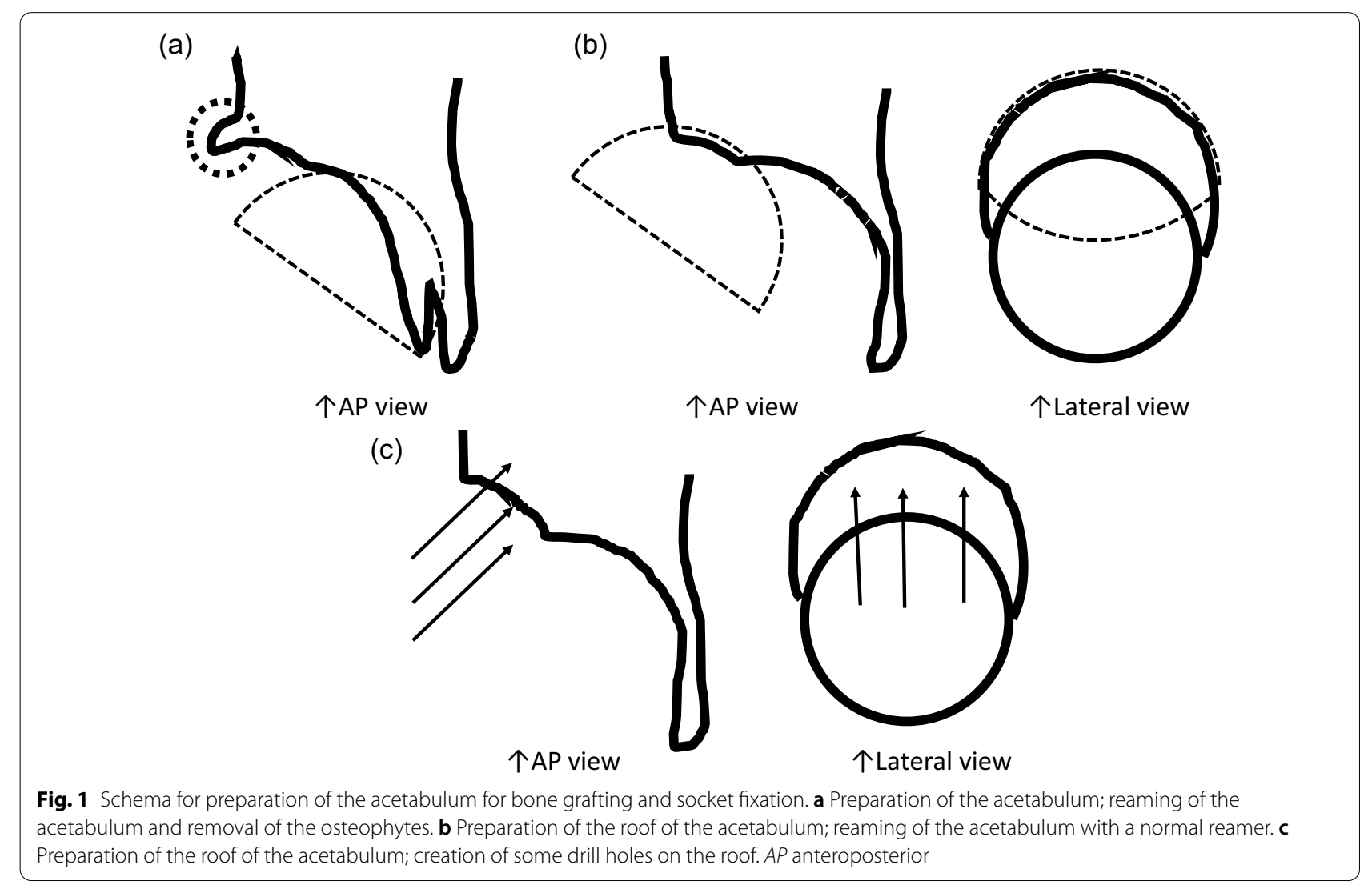



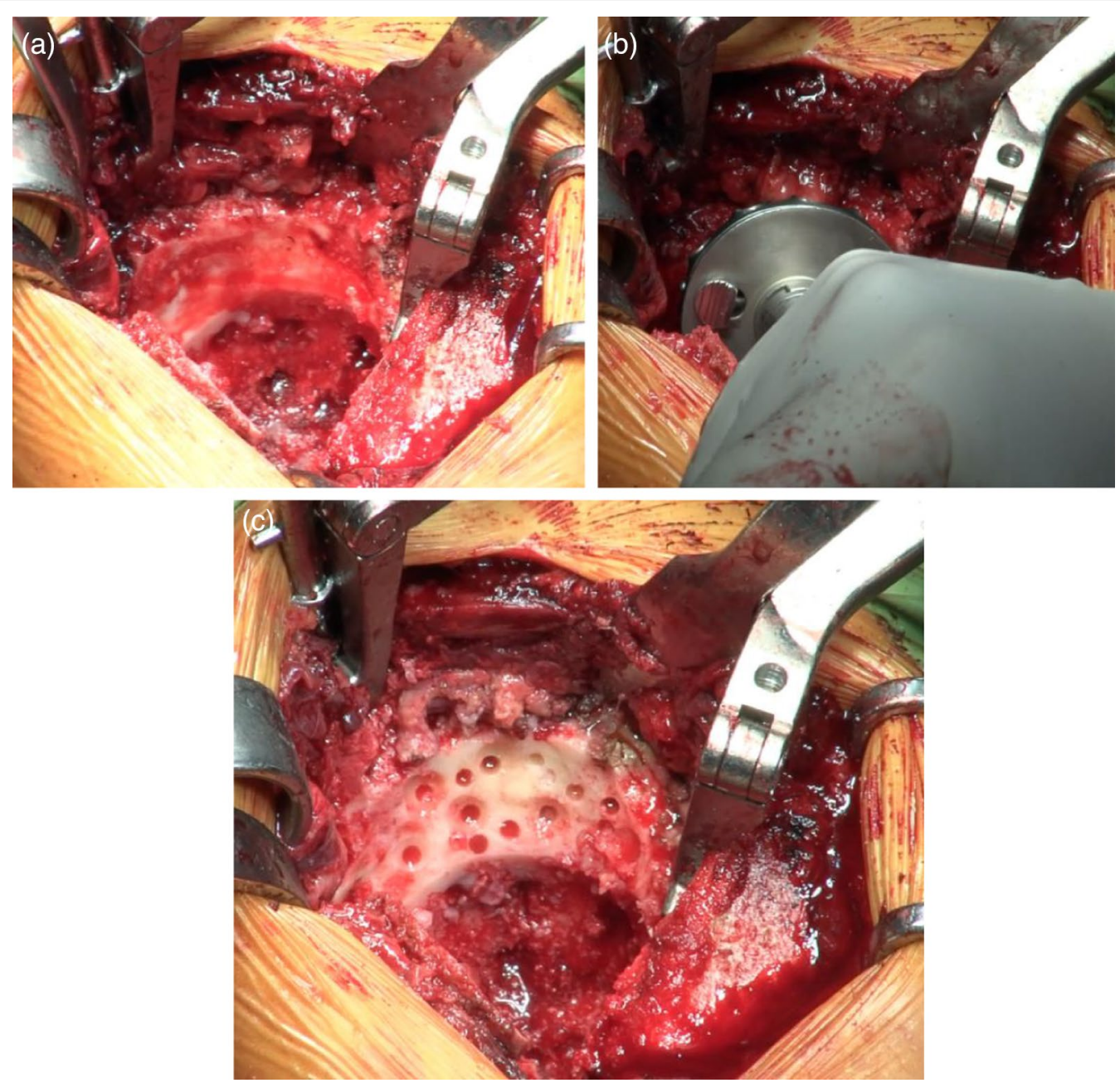

Fig. 2 Photographs showing preparation of the acetabulum for bone grafting and socket fixation. a The original acetabulum was reamed, and some anchoring holes were created. b The roof was reamed with a normal reamer. c Some drill holes were created on the roof

ering the curvature (Fig. 1b, 2b). After reaming, drill holes with diameters of 2.5 and $6 \mathrm{~mm}$ are created to vascularize the bony bed for transplantation. (Fig. 1c, 2c). The approximate size of the bone graft is checked with the trial socket.

4. Bone graft preparation

The inverted reamers (Femoral Head Reamer Set; Spierings Orthopaedics BVS, Nijmegen, Netherlands) are prepared (Fig. 3a). The inverted reamer is hemispherical, and unlike a normal reamer with blades located on the outer surface, the blades of the inverted reamer are located on the internal side. After fixing the resected femoral head on a bone fixator, the head is cut into one-third or half, depending on the size of the bony defect, to create a piece of bone. A weight-loaded (proximo-medial) part of the head is cut and trimmed for the graft. Then, the piece is reamed by the inverted reamer. The inverted reamer is $2 \mathrm{~mm}$ larger than the normal reamer that had been used for the roof of the acetabulum (this is described later in more detail). The surface of the trabecular bone is reamed by the inverted reamer to prepare a convex surface. The sclerotic cortical bone on the articular surface is preserved (Fig. 3b, 4). At grafting, the convex surface of the trabecular bone is placed on the medial side for attachment to the acetabulum, and that of the sclerotic bone is placed on the lateral side.

5. Bone transplantation and socket implantation After preparation, the piece can be press-fit into the defect of the acetabulum with good compatibility. Then, minced bone obtained during reaming of the acetabulum is applied on the surface of the trabecular bone of the piece (The side with minced bone 

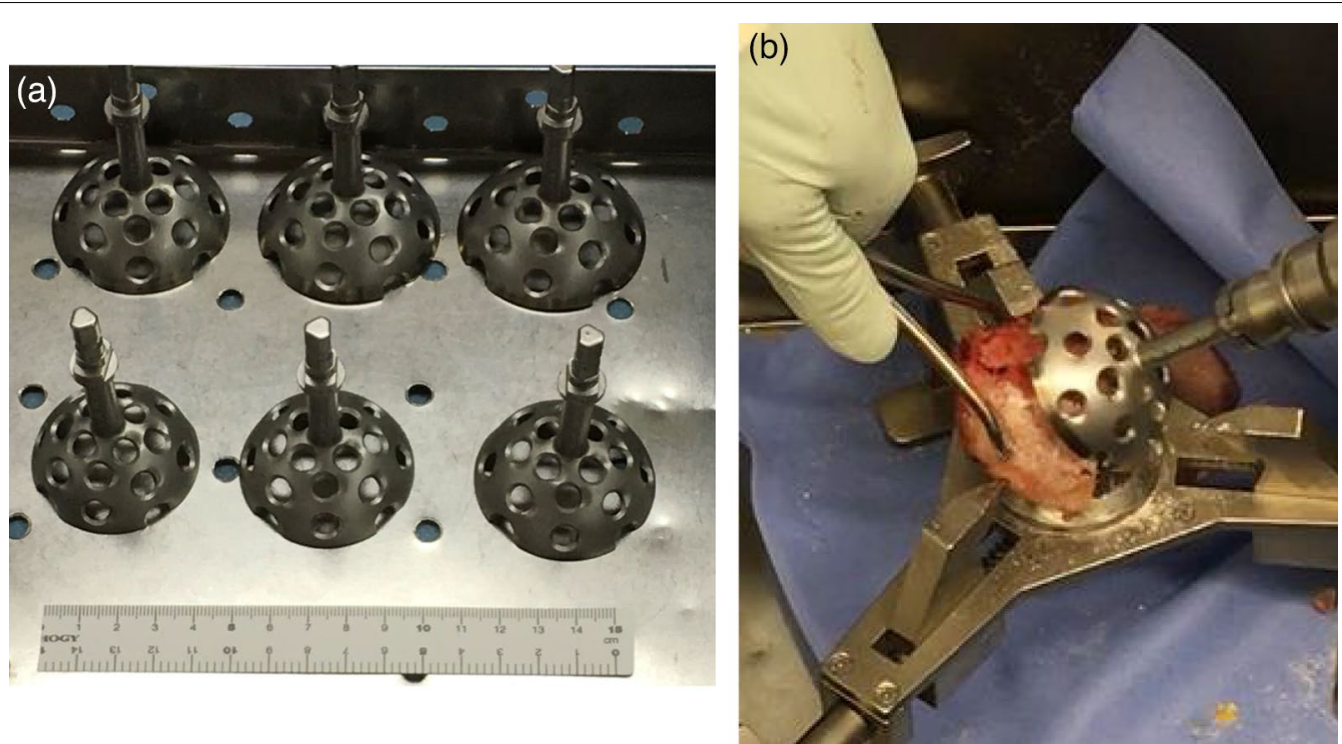

Fig. 3 Photographs showing the inverted reamer and shaving of the bone graft from the resected femoral head. a A photograph of the inverted reamer. $\mathbf{b}$ A piece of the femoral head was fixed on a bone fixator and reamed with the inverted reamer. The graft was shaved from the piece

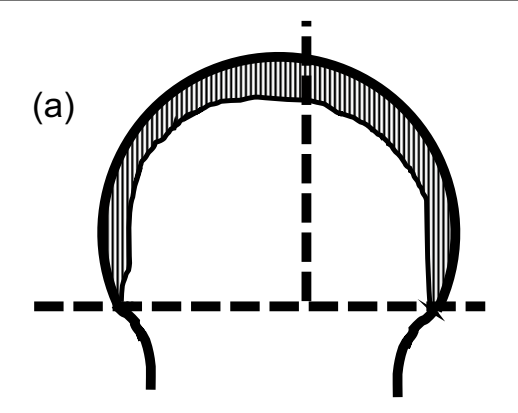

(b)

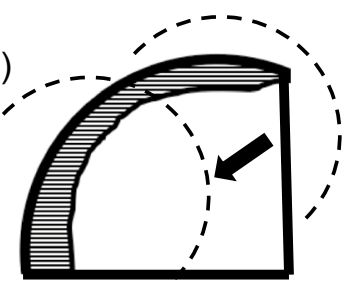

(c)

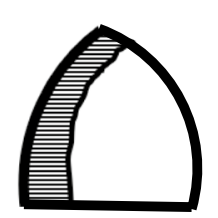

Fig. 4 Shaving of the bone graft from the resected femoral head. $\mathbf{a}$ The resected femoral head was cut into an adequate size. $\mathbf{b}$ The side of the trabecular bone in the piece of the femoral head was reamed with the inverted reamer, and extra bone was removed with a leur. The black arrow indicates the movement of the inverted reamer. c A piece with a convex surface was created. This piece will be transplanted onto the roof of the acetabulum. Sclerotic bone is shown as a stripe pattern. The dotted line is the cut line

will be medial and attached to the acetabulum). The piece with the minced bone is placed on the defect and fixed by two or three 2.0-mm Kirschner wires (K-wires) (Fig. 5a, 6a). Next, 1-3, 4.5-mm bioab- sorbable screws made of L-polylactic acid (Superfixorb; TEIJIN MEDICAL TECHNOLOGY CO., Osaka, Japan) are inserted with a washer instead of the K-wire one after another. When inserting the screws, the K-wires should be carefully bent to the lateral sides because straight $\mathrm{K}$-wires will obstruct screw insertion (Fig. 5b, 6b). Because an inferior part of the bone graft can be trimmed for socket fixation, these screws should be placed in the superior part of the graft. After inserting the screws, the acetabulum is reamed and trimmed for socket implantation again while taking care of the fixed bone graft (Fig. 6c). Then, the HXLPE non-flanged socket (STD socket; Kyocera Medical, Osaka, Japan) is implanted with polymethylmethacrylate (PMMA) bone cement (Fig. 5c, 6d). After the cement has hardened, all K-wires are carefully removed. Finally, the residual osteophytes around the socket, which may cause impingement and dislocation, are resected.

6. Postoperative rehabilitation

On the first postoperative day, the patients are allowed full weight-bearing dependent on their pain. Restrictions in weight-bearing are not required with this technique.

\section{Case presentation}

A 71-year-old woman underwent cTHA for secondary osteoarthritis (OA) with a dysplastic hip. The preoperative anteroposterior (AP) radiograph is shown in Fig. 7a. Her dysplastic hip was classified as Group III according to 

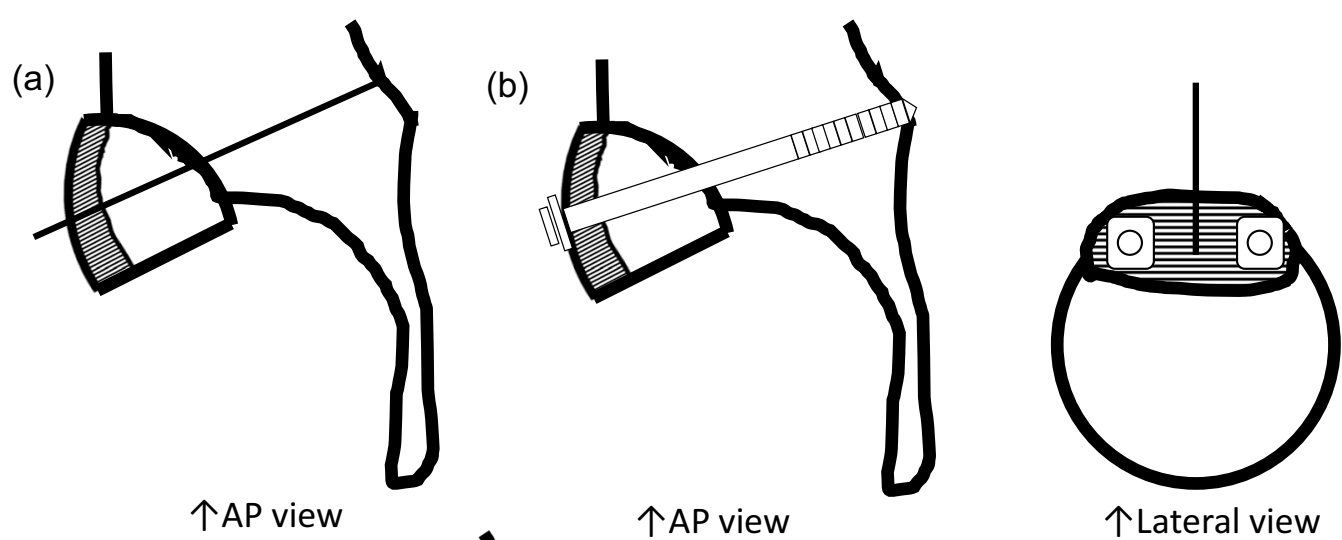

(c)

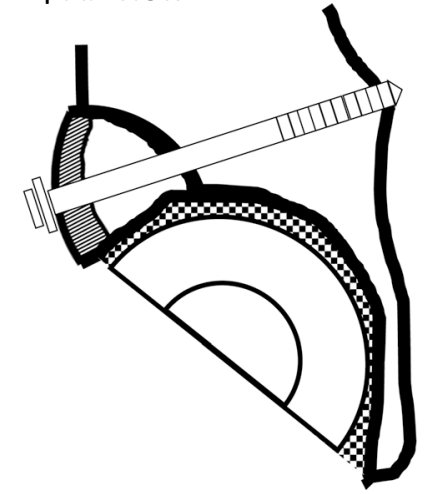

个AP view
个AP view

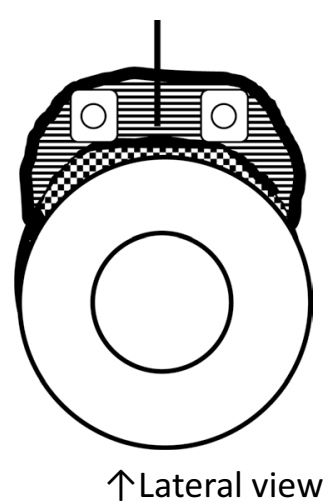

Fig. 5 The schema of transplantation of the bone graft and the socket. a The piece created with the inverted reamer was temporarily fixed with K-wires. $\mathbf{b}$ The piece was fixed by insertion of the bioabsorbable screws (Superfixorb ${ }^{\circledR}$ ). $\mathbf{c}$ The socket was fixed by cement. The K-wire was removed after the cement hardened. Sclerotic bone is shown as a stripe pattern. Cement is shown as the check pattern

Crowe's classification [21]. The acetabulum was reamed with a 46-mm normal reamer, and the roof of the acetabulum was reamed with a $48-\mathrm{mm}$ normal reamer. The bone graft was created using a 50 -mm inverted reamer. The graft was fixed with two Superfixorb screws. The head was $28 \mathrm{~mm}$ and the socket was $44 \mathrm{~mm}$ in diameter. The postoperative AP radiograph is shown in Fig. 7b. The AP radiograph at 2 years of follow up is shown in Fig. 7c. The bone coverage of the socket increased from $151^{\circ}$ to $180^{\circ}$ using this technique. The patient was allowed to walk with full weight-bearing on the first postoperative day.

\section{Discussion}

The present study has introduced a method to perform bone grafting using an inverted reamer. This method is useful because it allows surgeons to create the graft mechanically, which fits well into the defect. Moreover, bone graft creation with this method is faster than that with the conventional method, in which surgeons create bone grafts manually using a leur or a rotational burr. A previous report showed that the extent of socket coverage prevented late failure of the socket [22]. Thus, this method may improve the outcome of THA.

A report published in a German journal described a similar method along with the outcomes obtained in 55 hips [23]. However, only the abstract of that report is available in English. There are some differences between our proposed method and the method described in that report. First, the previous report does not clearly describe the relationship between the size of a normal reamer and that of an inverted reamer, while the inverted reamer is $2 \mathrm{~mm}$ larger than the normal reamer in our method. Second, the previous method uses no augmentation, including screws, routinely, while our method uses a couple of screws. Third, in the previously described method, postoperative non-weight bearing is recommended when the graft is larger than $10 \mathrm{~mm}$, while fullweight bearing is allowed in our method. Fourth, in the previous method, the articular cartilage was removed by an inverted reamer and the reamed surface was attached to the acetabulum to match the bony trabecular structure in the direction of weight-loading. In contrast, in our method, the unreamed surface (sclerotic bone) is placed 

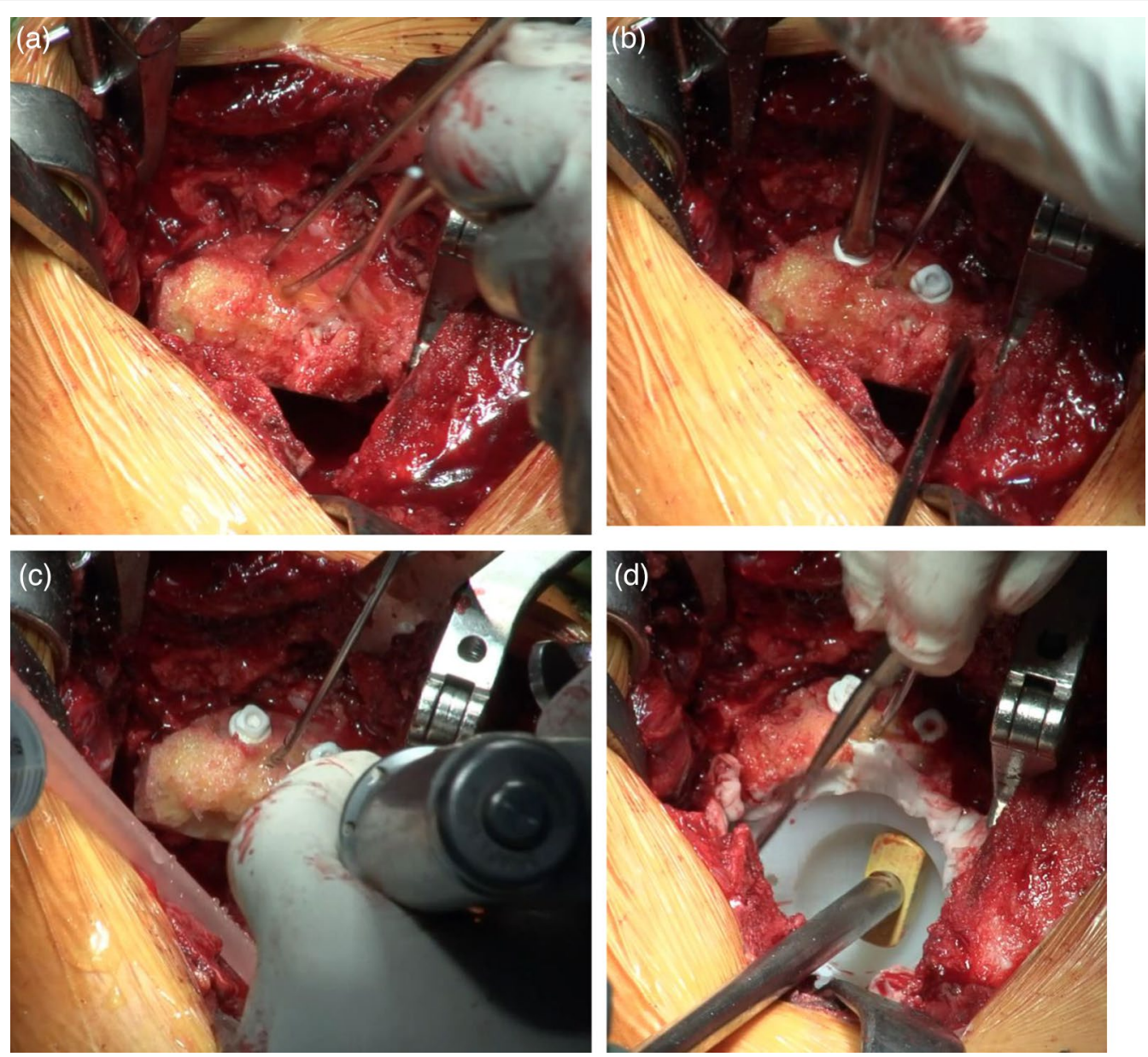

Fig. 6 Photographs showing transplantation of the bone graft and socket. a The piece created with the inverted reamer was temporarily fixed with K-wires. b The piece was fixed by insertion of bioabsorbable screws (Superfixorb ${ }^{\circledR}$ ). $\mathbf{c}$ The acetabulum was reamed again for socket fixation. $\mathbf{d}$ The socket was fixed by cement. The K-wire was removed after the cement hardened
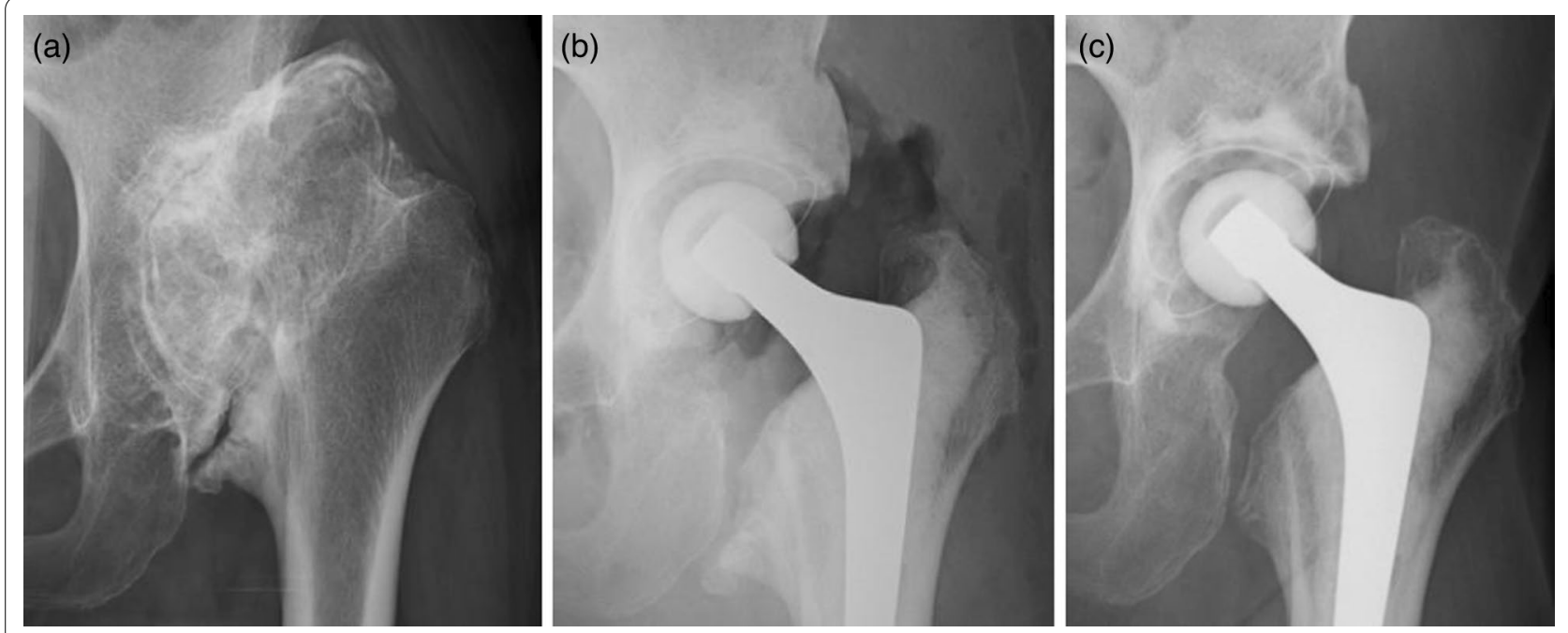

Fig. 7 AP radiographs of the patient who underwent CTHA via this method. a Preoperative AP radiograph. b Postoperative AP radiograph. Two Superfixorb screws, $35 \mathrm{~mm}$ and $45 \mathrm{~mm}$, were used. c AP radiograph at 2 years of follow-up 
on the lateral side, not attached to the acetabulum. To our knowledge, no other reports in the English literature have described a similar method.

A bioabsorbable screw with a washer was employed for graft fixation at our institute. The washer dissipates the pressure from the screw head and prevents the bone graft from being crushed. As an additional benefit, since the screw is bioabsorbable, it does not need to be removed during revision surgery. A previous report using a screw for a bone graft showed a good outcome [24]. Thus, these screws might show as much strength as a metal screw for fixation. Metal cancellous screws, including a cannulated screw, can also be used instead of the bioabsorbable screw in this method.

Five methods have been reported for dysplastic hips: proximal positioning of the socket, customized acetabular augments, combination with trabecular metal, bulk bone grafting on the roof of the acetabulum, and impaction bone grafting $[25,26]$. We advocated that bulk bone grafting is the best in terms of the bone stock and cup position. Kobayashi et al. presented a technique to enable the original anatomic placement of the cemented socket with a bulk bone autograft [27]. Some reports have shown excellent results of cTHA with acetabular bulk bone grafting [13-15]. In terms of the strength of the abductor muscle and long-term durability, anatomic placement of the socket is better, although there are objections to this approach $[28,29]$. Therefore, the achievement of anatomic placement of the socket with adequate bone grafting via our method may improve the outcome of CTHA for dysplastic hips.

This method involves three ingenuities. First, we applied minced bone on the graft. The minced bone can fill the gap to improve the stability of the graft and the osteosynthesis between the acetabulum and the graft, and also prevent cement intrusion into the gap between the graft and the host bone. Second, we reamed the graft using a 2-mm-larger inverted reamer. This allowed us to create a bone graft with a slightly larger diameter than the diameter of the defect and stabilized the graft in the defect by a press-fit mechanism. Third, the surface of the resected femoral head was utilized. The trabecular bone of the head was directed to the roof of the acetabulum because the trabecular bone is more bioactive for bone healing with the acetabulum. In contrast, the side of the sclerotic bone of the head was directed to the lateral side, since sclerotic bone may have more strength to endure loading by screw fixation. This technique was useful because it could yield good and robust stability immediately after fitting the graft on the roof of the acetabulum by matching the curvature.

However, this method has two drawbacks. First, we fixed the graft using a couple of screws. This procedure is time-consuming and might cause massive bleeding by damaging the intrapelvic vessels. Second, a larger exposure of the roof of the acetabulum is necessary for grafting. This may be difficult in patients with a small build and might damage a branch of the superior gluteal artery.

\section{Conclusions}

The "inverted reamer technique" introduced in this report is useful because it can easily and automatically create a well-fit graft. This method is simple and technically less demanding; it can be performed by every surgeon, including trainee and inexperienced surgeons. This method can improve the outcome of cTHA for dysplastic hips by preserving bone stock and increasing bone coverage of the socket implanted in the anatomic position.

\section{Abbreviations}

THA: Total hip arthroplasty; CTHA: Cemented total hip arthroplasty; HXLPE: Highly cross-linked polyethylene; K-wire: Kirschner wire; PMMA: Polymethylmethacrylate; AP: Anteroposterior.

\section{Acknowledgements \\ We would like to thank Editage (www.editage.com) for English language editing.}

\section{Author's contribution}

$\mathrm{HF}$ discovered the method. YO and HF wrote the article. HH, MK, YS and YM reviewed the article. All authors read and approved the final manuscript.

\section{Funding}

We have no funding. The authors did not receive support from any organization for the submitted work.

\section{Availability of data and materials}

These are available according to reader's request.

\section{Declarations}

Ethics approval and consent to participate

Not available.

\section{Consent for publication}

Not available.

\section{Competing interests}

The authors declare that they have no competing interest.

\section{Author details}

${ }^{1}$ Department of Orthopaedic Surgery, Kyoto Katsura Hospital, Kyoto, Japan. ${ }^{2}$ Center for Hip and Knee Arthroplasty, Department of Orthopaedic Surgery, Kyoto Rakuyo Hospital, Iwakura-Agura-cho 143, Sakyo-ku, Kyoto 606-0017, Japan. ${ }^{3}$ Department of Orthopaedic Surgery, Kyoto City Hospital, Kyoto, Japan. ${ }^{4}$ Department of Orthopaedic Surgery, Graduate School of Medicine, Kyoto University, Kyoto, Japan.

Received: 30 July 2021 Accepted: 24 October 2021

Published online: 30 October 2021 


\section{References}

1. Ling RSM, Charity J, Lee AJC, Whitehouse SL, Timperley AJ, Gie GA. The long-term results of the original Exeter polished cemented femoral component: a follow-up report. J Arthroplast. 2009;24:511-7.

2. Garellick G, Kärrholm J, Rogmark C, Herberts P. Swedish hip arthroplasty register: annual report, 2008. Dep Orthop Sahlgrenska Univ Hosp. 2009.

3. Corten K, Bourne RB, Charron KD, Au K, Rorabeck CH. What works best, a cemented or cementless primary total hip arthroplasty? Minimum 17-year followup of a randomized controlled trial. Clin Orthop Relat Res. 2011:469:209-17.

4. Streit MR, Innmann MM, Merle C, Bruckner T, Aldinger PR, Gotterbarm T. Long-term (20-to 25-year) results of an uncemented tapered titanium femoral component and factors affecting survivorship. Clin Orthop Relat Res. 2013:471:3262-9.

5. Petheram TG, Whitehouse SL, Kazi HA, Hubble MJW, Timperley AJ, Wilson MJ, et al. The Exeter Universal cemented femoral stem at 20 to 25 years: a report of 382 hips. Bone Joint J. 2016;98:1441-9.

6. Schulte KR, Callaghan JJ, Kelley SS, Johnston RC. The outcome of Charnley total hip arthroplasty with cement after a minimum twenty-year followup. The results of one surgeon. JBJS. 1993;75:961-75.

7. Okutani Y, Goto K, Kuroda Y, Kawai T, Okuzu Y, Kawata T, et al. Long-term outcome of cemented total hip arthroplasty with the Charnley-type femoral stem made of titanium alloy. J Orthop Sci. 2019;24:1047-52.

8. Callaghan JJ, Albright JC, Goetz DD, Olejniczak JP, Johnston RC. Charnley total hip arthroplasty with cement: minimum twenty-five-year follow-up. JBJS. 2000;82:487

9. Glyn-Jones S, Isaac S, Hauptfleisch J, McLardy-Smith P, Murray DW, Gill HS. Does highly cross-linked polyethylene wear less than conventional polyethylene in total hip arthroplasty? A double-blind, randomized, and controlled trial using roentgen stereophotogrammetric analysis. J Arthroplast. 2008;23:337-43.

10. Gaudiani MA, Ranawat AS, Ranawat CS. Wear analysis of highly cross-linked polyethylene in young and active patients at average fourteen years: a concise follow-up of a previous report. J Arthroplast. 2018;33:586-9.

11. Chougle A, Hemmady MV, Hodgkinson JP. Severity of hip dysplasia and loosening of the socket in cemented total hip replacement: a long-term follow-up. J Bone Jt Surg Ser B. 2005:87:16-20.

12. Mulroy RD Jr, Harris WH. Failure of acetabular autogenous grafts in total hip arthroplasty. Increasing incidence: a follow-up note. JBJS. 1990;72:1536-40.

13. lida $\mathrm{H}$, Matsusue $Y$, Kawanabe $K$, Okumura H, Yamamuro T, Nakamura T. Cemented total hip arthroplasty with acetabular bone graft for developmental dysplasia: long-term results and survivorship analysis. J Bone Joint Surg Br. 2000;82:176-84.

14. Inao S, Matsuno T. Cemented total hip arthroplasty with autogenous acetabular bone grafting for hips with developmental dysplasia in adults. J Bone Jt Surg Ser B. 2000;82:375-7.

15. Akiyama H, Kawanabe K, lida H, Haile P, Goto K, Nakamura T. Long-term results of cemented total hip arthroplasty in developmental dysplasia with acetabular bulk bone grafts after improving operative techniques. J Arthroplast. 2010;25:716-20
16. van der Donk S, Buma P, Slooff TJJH, Gardeniers JWM, Schreurs BW. Incorporation of morselized bone grafts: a study of 24 acetabular biopsy specimens. Clin Orthop Relat Res. 2002;396:131-41.

17. Schreurs BW, Arts JJC, Verdonschot N, Buma P, Slooff TJJH, Gardeniers JWM. Femoral component revision with use of impaction bone-grafting and a cemented polished stem. JBJS. 2005;87:2499-507.

18. Dall D. Exposure of the hip by anterior osteotomy of the greater trochanter. A modified anterolateral approach. J Bone Joint Surg Br. 1986;68:382-6.

19. Oe K, lida H, Kobayashi F, Ueda N, Nakamura T, Okamoto N, et al. Reattachment of an osteotomized greater trochanter in total hip arthroplasty using an ultra-high molecular weight polyethylene fiber cable. J Orthop Sci. 2018;23:992-9.

20. Fujita H, Hara H, Harada H, Kataoka M, Tominaga T, Nishimura R. Prospective, comparative study of cemented, smooth-surfaced titanium stems and polish-surfaced, stainless steel stems at a minimum follow-up of 10 years. Eur J Orthop Surg Traumatol. 2019;30:501-12.

21. Crowe JF, Mani VJ, Ranawat CS, et al. Total hip replacement in congenital dislocation and dysplasia of the hip. J Bone Jt Surg Am. 1979;61:15-23.

22. Shinar AA, Harris WH. Bulk structural autogenous grafts and allografts for reconstruction of the acetabulum in total hip arthroplasty: sixteen-yearaverage follow-up. JBJS. 1997;79:159-68.

23. Halder A, Beier A, Neumann W. Reconstruction of the acetabulum with structured bone graft in press-fit technique. Oper Orthop Traumatol. 2010:22:232-40.

24. Goto K, Akiyama H, Kawanabe K, So K, Morimoto T, Nakamura T. Longterm results of cemented total hip arthroplasty for dysplasia, with structural autograft fixed with poly-L-lactic acid screws. J Arthroplast. 2009:24:1146-51.

25. Maruyama M, Wakabayashi S, Ota H, Tensho K. Reconstruction of the Shallow Acetabulum With a Combination of Autologous Bulk and Impaction Bone Grafting Fixed by Cement. Clin Orthop Relat Res. 2017:475:387-95.

26. Iwase T, Morita D, Ito T, Takemoto G, Makida K. Favorable results of primary total hip arthroplasty with acetabular impaction bone grafting for large segmental bone defects in dysplastic hips. J Arthroplast. 2016;31:2221-6.

27. Kobayashi S, Saito N, Nawata M, Horiuchi H, lorio R, Takaoka K. Total hip arthroplasty with bulk femoral head autograft for acetabular reconstruction in DDH. J Bone Jt Surg Ser A. 2004;86:11-7.

28. Jerosch J, Steinbeck J, Stechmann J, Güth V. Influence of a high hip center on abductor muscle function. Arch Orthop Trauma Surg. 1997:1 16:385-9.

29. Watts CD, Abdel MP, Hanssen AD, Pagnano MW. Anatomic hip center decreases aseptic loosening rates after total hip arthroplasty with cement in patients with crowe type-II dysplasia: a concise follow-up report at a mean of thirty-six years. J Bone Jt Surg Am. 2016;98:910-5.

\section{Publisher's Note}

Springer Nature remains neutral with regard to jurisdictional claims in published maps and institutional affiliations.
Ready to submit your research? Choose BMC and benefit from:

- fast, convenient online submission

- thorough peer review by experienced researchers in your field

- rapid publication on acceptance

- support for research data, including large and complex data types

- gold Open Access which fosters wider collaboration and increased citations

- maximum visibility for your research: over 100M website views per year

At BMC, research is always in progress.

Learn more biomedcentral.com/submissions 